\title{
Zirconium Phosphate Catalysts in the XXI Century: State of the Art from 2010 to Date
}

\author{
Monica Pica \\ Department of Pharmaceutical Sciences, University of Perugia, Via del Liceo, 1, 06123 Perugia, Italy; \\ monica.pica@unipg.it
}

Academic Editor: Kevin J. Smith

Received: 2 May 2017; Accepted: 13 June 2017; Published: 19 June 2017

\begin{abstract}
An overview on the developments of zirconium phosphate $(\mathrm{ZrP})$ and its organic derivatives in heterogeneous catalysis in recent years is reported in the present review. Two basic aspects have been emphasized: first, the catalytic properties of zirconium phosphates were discussed, with particular attention to the effect of surface acidity and hydrophobic/hydrophilic character, textural properties, and particle morphology on the catalytic performances. Then, the use of zirconium phosphates as support for catalytic active species was reported, including organometallic complexes, metal ions, noble metal, and metal oxide nanoparticles. Zirconium phosphate plays, in those cases, a dual role, since it promotes the dispersion and stabilization of the catalysts, thanks to their interaction with the active sites on the surface of $\mathrm{ZrP}$, and facilitates the recovery and reuse of the catalytic species due to their immobilization on the solid support.
\end{abstract}

Keywords: zirconium phosphates; zirconium phosphonates; heterogeneous catalysis; catalyst support

\section{Introduction}

The chemistry of tetravalent metal phosphates and phosphonates has passed through the last sixty years, leaving important footprints in many fields. The key topic of this special issue is the use of zirconium phosphates in catalysis and this mini-review aims to collect the main contributions in this field since 2010 to date. In order to better understand the roles of zirconium phosphates in heterogeneous catalysis, the review will open with an introductory paragraph, describing its structural features, the synthetic approaches, and the functionalization strategies. Then, two sections will be devoted to the use of zirconium phosphates in catalysis; the first section deals with the role as catalyst itself in acid-catalyzed reactions, while the second investigates the use of zirconium phosphate as support for catalytic active species. The main aspects which make zirconium phosphate interesting in catalysis are:

- $\quad$ the presence of a robust inorganic structure which enables its application in relatively high temperature reactions;

- the presence of active sites on the particle surface whose features can be tuned according to the desired properties, by controlling the synthetic conditions or by introducing suitable functional groups covalently bonded the particle surface; they can be Bronsted acid or basic sites, Lewis basic sites, or metal coordinating sites.

- $\quad$ the possibility to control the textural properties, the surface area, and the porosity degree.

All these aspects are fundamental to the design of an efficient solid catalyst.

Starting from the state of the art, this special issue gives the opportunity to take a look at the future of zirconium phosphate-based catalysis, thanks to the original contributions of the authors that have been involved in it. 


\section{Zirconium Phosphate: Structural Features, Synthetic Approaches, and Functionalization Strategies}

The history of zirconium phosphates (hereafter ZrP) started in 1964, when Clearfield and Stynes first crystallized it by boiling the amorphous gel in phosphoric acid [1]. The obtained compound had a crystal structure of $\alpha$ type. A second crystalline phase, $\gamma$-phase, was obtained by Clearfield et al. in 1968 [2]. Both compounds have a layered structure. In the following, the description will concern only the $\alpha$-phase. The $\alpha$-zirconium monohydrogen phosphate phase has composition $\mathrm{Zr}\left(\mathrm{HPO}_{4}\right)_{2} \cdot \mathrm{H}_{2} \mathrm{O}$. Each layer consists of a plane of zirconium atoms, bridged by monohydrogenphosphate groups, lying above and below the main plane of $\mathrm{Zr}$ atoms [3]. The three oxygen atoms of the phosphate group are bonded to three different $\mathrm{Zr}$ atoms, while each zirconium is octahedrally coordinated by six oxygens. The $-\mathrm{OH}$ group of the monohydrogen phosphate groups points into the interlayer space and forms hydrogen bonds with the crystallization water molecules accommodated in the interlayer region. $\alpha-Z r P$ microcrystals consist of packed layers with an interlayer distance of $7.56 \AA$ (Figure 1).

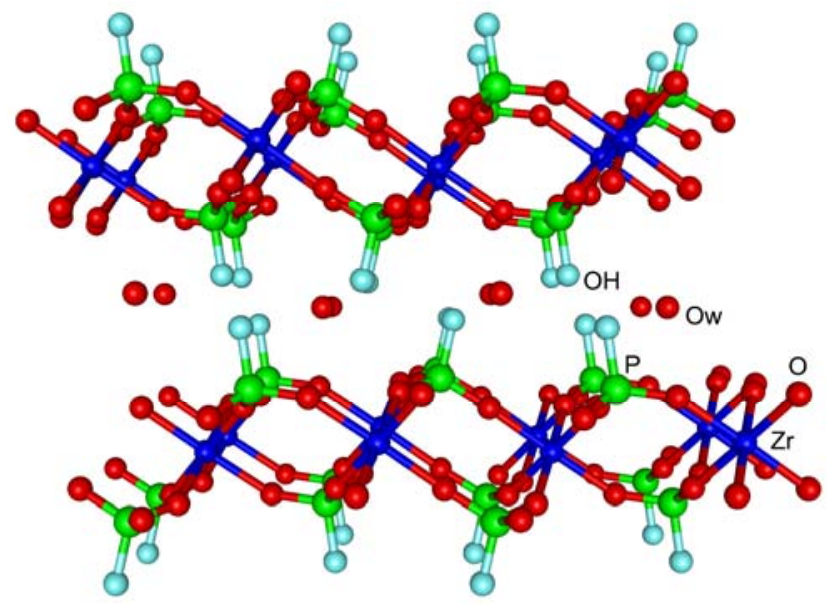

Figure 1. Chemical structure of $\alpha-\mathrm{ZrP}$.

Besides by refluxing amorphous $\mathrm{ZrP}$ with phosphoric acid, crystalline $\alpha$-ZrP can be also synthesized by using solutions containing soluble zirconium complexes and an excess of phosphoric acid [4,5]. The crystal precipitation occurs by slow decomplexation of $\mathrm{Zr}(\mathrm{IV})$ at temperature around $80^{\circ} \mathrm{C}$. Two main complexing agents are used, fluoride ions and oxalate ions. Both methods yield highly crystalline materials, having sizes in the range $5-10 \mu \mathrm{m}$ or in the range $2-3 \mu \mathrm{m}$, with $\mathrm{F}^{-}$or $\mathrm{C}_{2} \mathrm{O}_{4}{ }^{2-}$, respectively, as the complexing ion.

A derivative form of microcrystalline $\alpha-\mathrm{ZrP}$, named $\theta-\mathrm{ZrP}$, was also prepared, in order to promote the intercalation of bulky molecules into a $\alpha-\mathrm{ZrP}$ framework. It exists in a hydrated form of $\alpha-\mathrm{ZrP}$ containing approximately six hydration water molecules and exhibits a larger interlayer distance (about 10.3-10.4 $\AA$ ) with respect to the monohydrated form (7.6 $)$. This form was first observed by Clearfield et al. in 1969 [6], while Colon et al. developed a systematic approach for the use of $\theta$-ZrP for the intercalation of bulky molecules [7-9].

More recently, a new approach has been developed for the synthesis of nancrystalline $\alpha-Z r P$ [10]. Specifically, gels of $\alpha$-ZrP nanocrystals, made of alcohol intercalated nanoplatelets with hexagonal shape and a planar size of about $40 \mathrm{~nm}$, are obtained by simple addition of zirconyl propionate to phosphoric acid in aliphatic alcohols ("gel method"). Solvent elimination at $60{ }^{\circ} \mathrm{C}$ gave rise to an increase in the particle size: planar size and thickness ranged from 90 to $200 \mathrm{~nm}$ and from 20 to $85 \mathrm{~nm}$, respectively, depending on the nature of the solvent. The above procedure has several advantages: (i) the use of high temperatures and complexing agents is not needed; (ii) the intercalation of alcohol molecules, arranged in a bimolecular film according to the formula $\mathrm{Zr}\left(\mathrm{HPO}_{4}\right)_{2} \cdot 2 \mathrm{ROH}$, provokes an increase of the interlayer distance from $7.56 \AA$ to $14.4 \AA, 16.1 \AA$, $18.6 \AA$, when $\mathrm{ROH}$ = ethanol, propanol, 
or butanol, respectively. This enlargement of the interlayer region may facilitate the intercalation of guest species or ion exchange reactions.

The "gel method" also proved that nanosized $\mathrm{ZrP}$ has an unusual reactivity. It undergoes a phase transition at $120^{\circ} \mathrm{C}$, not observed with microcrystalline $\alpha-\mathrm{ZrP}$ in the same conditions, leading to a new $3 \mathrm{D}$ phase $\left(\tau^{\prime}-\mathrm{ZrP}\right)$, having formula $\mathrm{Zr}\left(\mathrm{HPO}_{4}\right)_{2}$ [11]. $\tau^{\prime}-\mathrm{ZrP}$ consists of cube-like nanoparticles and has a tetragonal unit cell made of packed chains of eight-membered rings, composed of $\mathrm{Zr}$ atoms connected to bridging $\mathrm{HPO}_{4}$ groups.

Nanoparticles of $\alpha$-ZrP can also be obtained by "precursor solutions", consisting of solutions of zirconyl propionate and phosphoric acid in proton acceptor polar solvents, such as DMF, DMA, or NMP [12]. These soluble precursors are transformed into the final $\mathrm{ZrP}$ product just by heating the solution to dryness, and this method resulted as particularly suitable for the preparation of polymer nanocomposites, since the filler precipitation occurred in the presence of the polymer, thus promoting the filler dispersion within the polymer matrix and the polymer-filler interaction.

Regarding catalysis, many efforts have been devoted to the synthesis of zirconium phosphate with mesoporous textural properties, providing large surface area and a high number of surface active sites. As an example, Torres et al. reported in 1998 a templated synthesis of a new mesoporous zirconium phosphate with uniform pore dimensions and acidic properties [13]. The synthesis was carried out by adding zirconium n-propoxide to a solution of phosphoric acid in the presence of cetyltrimethylammonium bromide. Surface areas of 326 and $251 \mathrm{~m}^{2} \mathrm{~g}^{-1}$ were obtained for the sample extracted with $\mathrm{HCl}$ /ethanol and calcined at $550{ }^{\circ} \mathrm{C}$ in air (to remove the surfactant), respectively. The ${ }^{31} \mathrm{P}$ MAS highlighted the presence of tetrahedral phosphates having connectivity one, two, three, and four with $\mathrm{Zr}(\mathrm{IV})$. Thermoprogrammed desorption of ammonia showed, for the sample extracted with $\mathrm{HCl}$ /ethanol, the presence of medium to strong acid sites, which may be attributed to surface $\mathrm{POH}$ [and $\mathrm{P}(\mathrm{OH})_{2}$ ] groups, which could exchange protons with other cationic species. The calcined sample exhibited a decrease in acidity with respect to that extracted with $\mathrm{HCl}$ /ethanol, and this must be related to the condensation of neighboring hydrogen phosphate groups. In the following section the catalytic properties of mesoporous zirconium phosphates, prepared by using different templating agents, will be discussed.

The possibility to anchor to the $\alpha$-type layers a large variety of phosphonate groups, without significantly modifying the layer structure, represents another powerful strategy for the design of tailor-made catalysts.

Inorgano-organic zirconium phosphate/phosphonates, with the general formula $\mathrm{Zr}\left(\mathrm{O}_{3} \mathrm{PR}\right)_{x}\left(\mathrm{O}_{3} \mathrm{PR}^{\prime}\right)_{2-\mathrm{x}}$, where $\mathrm{R}$ and $\mathrm{R}^{\prime}$ are an inorganic (e.g., $\left.-\mathrm{H},-\mathrm{OH}\right)$ and/or organic (e.g., $-\mathrm{CH}_{3},-\mathrm{C}_{6} \mathrm{H}_{5},-\mathrm{C}_{6} \mathrm{H}_{4} \mathrm{SO}_{3} \mathrm{H},-\mathrm{O}\left(\mathrm{CH}_{2}\right),-\mathrm{CH}_{3}$, etc.) groups, are generally synthesized by the same procedures for the synthesis of $\alpha-\mathrm{ZrP}$, by using phosphonic acid solutions, or phosphoric/phosphonic acid solutions as source of ligands for $\mathrm{Zr}$ (IV) [14]. Phosphonate groups bearing sulfonic acid groups are generally used to increase the catalyst surface acidity, while hydrophobic phosphonates are covalently linked to the inorganic layer in order to modulate the hydrophobic/hydrophilic character of the catalyst surface.

Recently, it was found that zirconium phosphate/phosphonates can be also synthesized by topotactic anion exchange reaction of the phosphate groups of nanosized $\mathrm{ZrP}$ with phosphonate groups. Specifically, the procedure consists in the reaction between a gel of propanol intercalated nanosized $\mathrm{ZrP}$ with alcoholic/aqueous solutions of the desired phosphonic acid. This quick and mild procedure allowed the phosphate groups of nanosized $\mathrm{ZrP}$ to partially be replaced with phosphonate groups, obtaining, for the first time, single-phase mixed zirconium phosphate phosphonates, with the phosphonate groups randomly distributed on the $\alpha$-type layers. According to this procedure, compounds having composition $\mathrm{Zr}\left(\mathrm{O}_{3} \mathrm{PR}\right)_{x}\left(\mathrm{O}_{3} \mathrm{POH}\right)_{2-x}$, with $\mathrm{R}=-\left(\mathrm{CH}_{2}\right)_{n} \mathrm{CH}_{3} ;-\mathrm{C}_{6} \mathrm{H}_{5} ;-\left(\mathrm{CH}_{2}\right)_{2} \mathrm{NH}_{2}$, etc., have been successfully synthesized $[15,16]$.

Organic derivatives of $\mathrm{ZrP}$ can be obtained also by reaction between the - $\mathrm{POH}$ groups of the layers with epoxides, leading to $-\mathrm{P}-\mathrm{O}-\mathrm{C}$ bonds [17-20]. Zirconium organo-phosphates, bearing 
long alkyl chains covalently bonded on the layer surface, were successfully obtained by using both microcrystalline and nanocrystalline $\alpha$-ZrP. In order to promote the reactions, gels of partially exfoliated $\mathrm{ZrP}$ in a non-aprotic solvent, such as THF, were used. When 1,2-epoxydodecane was used as reactant with microcystalline $\mathrm{ZrP}$, the nucleophilic attack of $\mathrm{POH}$ mainly occurred to carbon 1 and, to a lesser extent, to carbon 2 of epoxydodecane [17]. The number of alkyl chains per $\mathrm{Zr}$ atom, $\mathrm{x}$, of the $\mathrm{ZrP}$ organic derivatives was increased from 0.5 to 2.0 and it was found that the interlayer distance increased continuously, from $\sim 20$ to $\sim 35 \AA$.

\section{Zirconium Phosphate/Phosphonates as Heterogeneous Catalysts}

The catalytic properties of $\mathrm{ZrP}$ are well known and have been extensively investigated, especially in acid-catalyzed reactions such as dehydration, isomerization, and esterhydrolysis reactions, due to its high thermal stability, high water tolerance ability, and easy recovery [21].

It is known that the performance of solid catalysts and also catalyst supports is generally dependent on their morphology, surface area, and architecture. In this regard, ZrP particles with different morphologies and textural features, such as microsphere and mesoporous structures, have been investigated for heterogeneous catalysis.

$\mathrm{ZrP}$ microspheres were obtained by Zhang et al. through a spray-drying process, by using $\alpha$-ZrP nanoparticles synthesized according to a separate nucleation and aging step procedure [22]. The final product, obtained by calcination at $300^{\circ} \mathrm{C}$, is composed of nanosized $\alpha-\mathrm{ZrP}$ particles aggregated into solid microspheres with a diameter of $5-45 \mu \mathrm{m}$ and a sphericity of 0.80 . The number of accessible acidic sites of this material is higher than that of powered microcrystalline $\alpha$-ZrP, due to its higher surface area with respect to the powder $\left(43.8 \mathrm{~m}^{2} \mathrm{~g}^{-1} \mathrm{vs} .35 .6 \mathrm{~m}^{2} \mathrm{~g}^{-1}\right)$ and to the macroporous structure which allowed exposure to more spatial voids and a higher number of active sites on the wall of the macropore. The catalytic properties of the $\mathrm{ZrP}$ microspheres were tested in the acylation reaction for the synthesis of stearic acid monoethanolamide using methyl stearate and ethanolamine as raw materials. About $92.9 \%$ of methyl stearate conversion was reached at $120^{\circ} \mathrm{C}$ after $12 \mathrm{~h}$, while just $45 \%$ of conversion was obtained with powered $\mathrm{ZrP}$.

Mesoporous $\mathrm{ZrP}(\mathrm{m}-\mathrm{ZrP})$ has been also proposed as solid acid catalyst with a surface area in the range of $200-500 \mathrm{~m}^{2} \mathrm{~g}^{-1}$.

It is generally prepared by a post-synthesis method in basic conditions, by using a surfactant agent (for example cetyltrimethylammonium bromide, CTAB), phosphate salts and zirconium oxy-chloride or zirconium alkoxide as zirconium source [23-25], followed by calcination, generally at a temperature in the range $400-600{ }^{\circ} \mathrm{C}$.

Sinhamahapatra et al. [23] studied the textural properties like specific surface area and average pore size distribution of $\mathrm{m}-\mathrm{ZrP}$ materials synthesized in the presence of CTAB by a post-synthesis method, with a phosphate to zirconium molar ratio in the range $0.25-3.0$. They found that $\mathrm{m}-\mathrm{ZrP}$ samples were obtained by using a phosphate to $\mathrm{Zr}$ molar ratio in the range of $0.5-2.5$ : they exhibited similar surface area (391-407 $\left.\mathrm{m}^{2} \mathrm{~g}^{-1}\right)$ as well as pore size $(2.9-2.8 \mathrm{~nm})$, while the $\mathrm{P} / \mathrm{Zr}$ molar ratio was in the range $0.42-1.93 .{ }^{31} \mathrm{P} N M R$ analysis of the $\mathrm{m}$-ZrP samples showed changes in the environment of the phosphate group on calcinations, specifically, an increase in the phosphate connectivity toward $\mathrm{Zr}(\mathrm{IV})$, which was nearly independent of the phosphate amount used for the synthesis. Diffuse reflectance FT-IR (DRIFT) and $\mathrm{NH}_{3}$-Temperature programmed desorption (TPD) studies proved the presence of both Bronsted and Lewis acid sites, tunable with phosphate loading.

They postulated that the Brønsted acid sites possibly arise from geminal $\mathrm{P}(\mathrm{OH})$ groups, while the Lewis acid centers could be attributed to $\mathrm{Zr}^{4+}[26,27]$. Moreover, they found that the total acidity decreased with increasing the calcination temperature to the range $450-550{ }^{\circ} \mathrm{C}$.

Mugweru and collaborators prepared a m-ZrP by a post-synthesis method by using CTAB as a cationic pore directing agent, a phosphate to $\mathrm{Zr}$ molar ratio $=2$, and a calcination temperature of $550{ }^{\circ} \mathrm{C}$ [23]. The mesoporous product has a specific surface area of $407 \mathrm{~m}^{2} \mathrm{~g}^{-1}$, and a narrow pore size in the range $2-3 \mathrm{~nm}$. 
Bhaumik et al. proposed in 2011 an alternative method for the synthesis of $\mathrm{m}-\mathrm{ZrP}$ based on the evaporation induced self-assembly (EISA) method by using non-ionic Pluronic F127 as a structure directing agent in an acidic non-aqueous medium, zirconium-(IV) butoxide and phosphoric acid [28]. Mesoporous ZrP materials, with P/Zr molar ratios 1.1 and 0.7, were obtained, which exhibited high surface area $\left(260-312 \mathrm{~m}^{2} \mathrm{~g}^{-1}\right)$, larger pore size $(\sim 5.0 \mathrm{~nm})$ with respect to the material obtained by post-synthesis method, and strong Lewis and Bronsted acid sites, thus reducing the probability of pore blocking and inhomogeneity problem [26].

Xue et al. synthesized $\mathrm{m}-\mathrm{ZrP}$ by a hydrothermal method and by using dodecylamine and hexadecylamine [29]: ZrP obtained after calcination possesses a high surface area $\left(316 \mathrm{~m}^{2} \mathrm{~g}^{-1}\right)$ and rich mesoporosity, with uniform pore width of $\approx 2 \mathrm{~nm}$ in the morphology of nanoaggregates. The open structure of this $\mathrm{m}-\mathrm{ZrP}$ exhibited several Brønsted and Lewis acid active sites.

Mesoporous $\mathrm{ZrP}$ has been used in several catalytic reactions, including the synthesis of industrially important chemicals, biomass utilization, and biodiesel production.

The literature data reported below are summarized in Table 1.

Table 1. Summarizing table on the use of zirconium phosphates and its organic derivatives as heterogeneous catalysts in acid-catalyzed reactions.

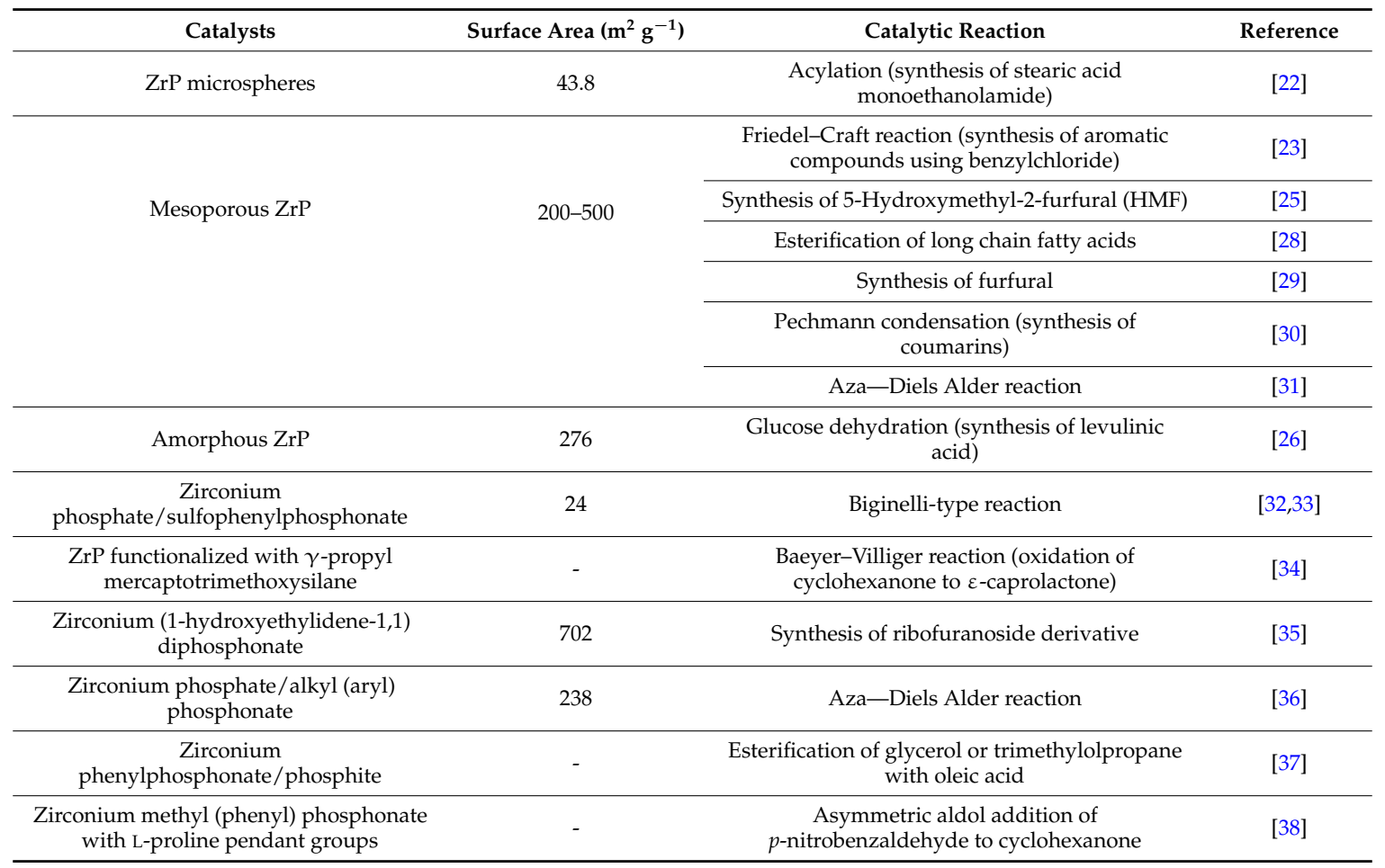

Sinhamahapatra et al. evaluated the catalytic properties of $\mathrm{m}-\mathrm{ZrP}$ in the benzylation reaction (Friedel-Craft reaction) of aromatic compounds using benzylchloride as the benzylating agent in solvent free conditions [23]. A 94\% conversion of benzylchloride with 100\% selectivity for di-phenyl methane in the benzylation of benzene was reached. Among other factors, both the phosphate amount in $\mathrm{m}-\mathrm{ZrP}$ and temperature affected the conversion and selectivity of the reaction. The conversion increased with the phosphate amount, the catalyst acidity, and temperature (in the range $70-110{ }^{\circ} \mathrm{C}$ ), without compromising the selectivity. At higher temperatures the conversion significantly decreases, due to the formation of the di-benzylated product. The catalytic activity of $\mathrm{m}-\mathrm{ZrP}$ is much higher than that of layered $\mathrm{ZrP}$, and it can be recycled at least six times without significant loss of its catalytic activity.

They also tested $\mathrm{m}-\mathrm{ZrP}$ in the synthesis of coumarins via a Pechmann condensation reaction by using different phenols as substrates [30]. Among the substituted phenols, m-amino phenol was found to be more reactive than other phenols and a 100\% conversion with $100 \%$ selectivity of 7 -amino 
4-methyl coumarin was obtained at $110^{\circ} \mathrm{C}$ for $30 \mathrm{~min}$ by a conventional heating method, while the same degree of conversion was reached in $10 \mathrm{~min}$ by microwave assisted reaction.

Bhaumik et al. tested their $\mathrm{m}-\mathrm{ZrP}$ with large pore size (around $5 \mathrm{~nm}$ ) in the biodiesel reaction for the effective conversion of long chain fatty acids to their respective methyl esters [28]. The best results were obtained for the $\mathrm{m}-\mathrm{ZrP}$ with the higher $\mathrm{P} / \mathrm{Zr}$ molar ratio (1.1) which showed very good catalytic performance in the esterification of lauric, myrestic, palmitic, and stearic acid with methanol, and the conversion rates were $74.4 \%, 86.41 \%, 75.5 \%$, and $74.2 \%$, respectively. Moreover, it has been recycled five times without significant loss of activity.

The conversion of sugars to organic intermediates in the aqueous-phase is an important issue for the utilization of biomass. Xue et al. employed their $\mathrm{m}-\mathrm{ZrP}$ in the xylose dehydration to furfural in aqueous-phase, thus obtaining high conversions up to $96 \%$ and high furfural yields up to $52 \%$ in $2 \mathrm{~h}$ [29]. The reuse properties of $\mathrm{m}-\mathrm{ZrP}$ were also tested, proving that the thermal treatment between reuse intervals basically regenerates the catalyst performance.

Also, Mugweru and collaborators examined the catalytic activity of a m-ZrP, prepared by a post-synthesis method (specific surface area of $407 \mathrm{~m}^{2} \mathrm{~g}^{-1}$, pore size in the range $2-3 \mathrm{~nm}$ ), in the conversion of fructose, glucose, and sucrose to 5-Hydroxymethyl-2-furfural (HMF) under various reaction conditions [25]. The best results were obtained by using fructose as substrate, in a water-diglyme solvent system $(1: 3, v / v)$, in the presence of $\mathrm{NaCl}$ as a co-catalyst (because of the improvement of the partitioning of HMF into the extracting phase by means of the salting out effect), and at $150{ }^{\circ} \mathrm{C}$ : in these conditions, the HMF yield reached $80 \%$.

Piermatti et al. investigated, for the first time, the catalytic effectiveness of a mesoporous $\mathrm{ZrP}$ as recyclable Brønsted-acid catalyst in the aza-Diels-Alder reaction of N-PMP-benzaldimines with Danishefsky's diene under solvent-free conditions, in the presence of a catalytic amount of sodium dodecylsulfate (SDS) [31]. Despite the relatively low surface area of the catalyst in comparison with other mesoporous $\mathrm{ZrP}$ samples $\left(83 \mathrm{~m}^{2} \mathrm{~g}^{-1}\right)$, the reaction was fast and highly chemoselective, with high yields of 2,3-dihydro-4-pyridones. The recycling of the entire ZrP/SDS catalytic system gave very satisfactory results with a $99 \%$ of conversion and $100 \%$ selectivity toward dihydro-4-pyridone after five cycles.

An interesting work was carried out by Weingarten et al. [26] on the characterization of the different catalytic sites on metal (IV) phosphate solid acid catalysts and on the identification of their roles in catalyzing the aqueous phase dehydration of glucose to levulinic acid. They precipitated three amorphous zirconium phosphates from aqueous medium by reaction of $\mathrm{ZrOCl}_{2} \cdot 8 \mathrm{H}_{2} \mathrm{O}$ with different amounts of $\mathrm{NH}_{4} \mathrm{H}_{2} \mathrm{PO}_{4}$ at room temperature, followed by calcination at $400{ }^{\circ} \mathrm{C}$. Among the obtained compounds, the product labeled as $\mathrm{ZrP} 2$ exhibited the higher $\mathrm{P} / \mathrm{Zr}$ molar ratio $(\approx 2)$, the higher surface area $\left(276 \mathrm{~m}^{2} \mathrm{~g}^{-1}\right)$, together with the higher fraction of hydroxyl Brønsted acid sites lying on the catalyst surface. In contrast, the sample labeled as $\mathrm{ZrP1}$ exhibited the higher fraction of Lewis acid sites as a consequence of the higher zirconium loading, which means the higher amount of $\mathrm{Zr}^{4+}$ species. The catalytic properties of $\mathrm{ZrP}$ were tested in a glucose dehydration reaction at $160{ }^{\circ} \mathrm{C}$ in the aqueous phase to produce levulinic acid: this is a three step reaction, passing through the formation of fructose and mannose (isomerization) and HMF (dehydration). Interestingly, $\mathrm{ZrP} 2$ exhibited the highest selectivity toward HMF and levulinic acid and the lowest selectivity toward humins, which are considered as all unidentified water soluble and insoluble compounds. These results are strictly connected to the fraction of Bronsted acid sites on the catalyst surface. HMF and levulinic acid production increases with the amount of Brønsted acid sites, while a higher rate of glucose disappearance and lower selectivity to HMF and levulinic acid are observed for catalysts with increasing the Lewis sites.

The acidity of the surface active sites of $\mathrm{ZrP}$ can be improved by anchoring strong acid groups, such as sulfonic groups, on the catalyst surface. Layered $\alpha$-type zirconium phosphate offers the possibility to anchor the desired functional group on single layer $\mathrm{ZrP}$ nanosheets, due to the possibility to obtain colloidal dispersion of $\mathrm{ZrP}$ by exfoliation in suitable conditions. 
Zirconium sulfophenyl phosphonates of $\alpha$-type are a class of organic derivatives of $\mathrm{ZrP}$. They have the same layer structure of $\alpha-\mathrm{ZrP}$, in which the phosphate groups are totally or partially replaced by sulfophenyl phosphonate groups and/or other organic phosphonates. The general formula of these compounds is $\mathrm{Zr}\left(\mathrm{O}_{3} \mathrm{PR}\right)_{x}\left(\mathrm{O}_{3} \mathrm{PC}_{6} \mathrm{H}_{4} \mathrm{SO}_{3} \mathrm{H}\right)_{2-\mathrm{x}}$, where $\mathrm{R}=-\mathrm{OH}$ or an organic group [32].

They are generally obtained by direct synthesis, by mixing a solution of a zirconyl salt with a solution of the desired mixture of phosphoric/phosphonic acids. Rosati et al. reported the use of $\alpha$-zirconium sulfophenylphosphonate, $\mathrm{Zr}\left(\mathrm{O}_{3} \mathrm{PCH}_{3}\right)_{1.2}\left(\mathrm{O}_{3} \mathrm{PC}_{6} \mathrm{H}_{4} \mathrm{SO}_{3} \mathrm{H}\right)_{0.8}$, $(\mathrm{pKa}$ between -5.6 and -8.4: measured by Hammet acidity, and a surface area of $24 \mathrm{~m}^{2} \mathrm{~g}^{-1}$ ) in the Biginelli type reaction, in solvent free condition, between $\beta$-dicarbonyl compounds with aromatic aldehydes and urea at $80^{\circ} \mathrm{C}$ to obtain 3,4-dihydropyrimidin-2(1H)-one derivatives [33]. The yields were in the range $78-92 \%$, for reaction times of $18-20 \mathrm{~h}$.

Sun et al. published an interesting paper in 2014 on the functionalization of exfoliated $\mathrm{ZrP}$ with $\gamma$-propyl mercaptotrimethoxysilane, leading to the formation of $\mathrm{P}-\mathrm{O}-\mathrm{Si}$ covalent bonds on the layer surface, as proved by high resolution X-ray photoelectron spectroscopy (XPS) and Fourier transform infrared spectroscopy (FTIR) analysis [34]. The sulfonic group was obtained by oxidation of the mercapto group with oxygen peroxide, followed by vacuum drying and grinding. The degree of surface functionalization was estimated to be around $58 \%$. The highly acidic catalyst has been tested in the Baeyer-Villiger oxidation of cyclohexanone to $\varepsilon$-caprolactone by $\mathrm{H}_{2} \mathrm{O}_{2}$ under various conditions. The best result was achieved with $0.20 \mathrm{~g}$ of catalyst per $4.0 \mathrm{mmol}$ cyclohexanone and $10.0 \mathrm{mmol}$ $\mathrm{H}_{2} \mathrm{O}_{2}$, thus reaching $80 \%$ yield after $12 \mathrm{~h}$ of reaction both with and without $\mathrm{CH}_{3} \mathrm{CN}$ as a solvent. The possibility of reaching high reaction yield in solvent-free conditions is highly desirable for most industrial processes. The solid catalyst was easily separated from the products and recycled up to at least 7 times without significant loss of catalytic activity.

A mesoporous zirconium phosphonate (ZrHEDP) with a high surface area of $702 \mathrm{~m}^{2} \mathrm{~g}^{-1}$ and a uniform pore size of $3.6 \mathrm{~nm}$, was obtained by Yuan et al. by reaction of 1-hydroxyethylidene-1,1-diphosphonic acid (HEDP) with zirconium oxychloride in water, in the presence of cetyltrimethylammonium bromide as a cationic surfactant [35]. ${ }^{31} \mathrm{P}$ MAS NMR, ion exchange capacity determination, XPS, and elemental analysis provided the following composition $\mathrm{Zr}\left(\mathrm{O}_{3} \mathrm{PC}\left(\mathrm{CH}_{3}\right)(\mathrm{OH}) \mathrm{PO}_{2}\right)_{1.5} \cdot x \mathrm{H}_{2} \mathrm{O}$, where the $\mathrm{RPO}_{2}(\mathrm{OH})$ species of the framework could be accessible as catalytic acid sites. In order to test this possibility, mesoporous ZrHEDP was employed as a solid-acid catalyst in the synthesis of methyl-2,3-O-isopropylidene- $\beta$-D-ribofuranoside, an important intermediate for the preparation of several nucleosides that exhibit a variety of biological functions. A yield of $35.6 \%$ was reached after $3 \mathrm{~h}$ at $70{ }^{\circ} \mathrm{C}$. Moreover, the catalytic activity of ZrHEDP remained practically unchanged for at least five cycles.

X-ray diffraction XRD and multi-point Brunauer-Emmett-Teller (BET) analysis revealed that the mesoporous structure remained almost unaltered after the fifth cycle, since the used catalyst still has a surface area of $680 \mathrm{~m}^{2} \mathrm{~g}^{-1}$ with a pore diameter of $3.6 \mathrm{~nm}$.

In many reactions, the presence of hydrophobic groups on the catalyst surface can steer the reagents to the active sites, thus also avoiding the use of ionic surfactants such as SDS. In light of this, zirconium hydrogen phosphonates with hydrophobic groups have been employed as heterogeneous catalysts. Lanari et al. prepared several zirconium phosphate phosphonates, having general formula $\mathrm{Zr}\left(\mathrm{O}_{3} \mathrm{POH}\right)_{2-\mathrm{x}}\left(\mathrm{O}_{3} \mathrm{PR}\right)$, where $\mathrm{R}$ is hydrophobic $(\mathrm{R}=$ methyl, propyl, phenyl) to modulate the hydrophobicity of the corresponding catalyst's surface [36]. Their catalytic activities were tested in the direct aza-Diels-Alder reaction in water of 2-cyclohexen-1-one with $N$-PMP-p-chloro benzaldimine, without any other additive. This is an effective route to the synthesis of isoquinuclidines that are the structural elements of numerous naturally occurring alkaloids with interesting biologic properties. The best results were obtained with $\mathrm{R}=\mathrm{Me}$ and $\mathrm{Ph}$, having composition $\mathrm{Zr}\left(\mathrm{PO}_{3} \mathrm{OH}\right)_{0.37}\left(\mathrm{PO}_{3} \mathrm{Me}\right)_{0.65}\left(\mathrm{PO}_{3} \mathrm{Ph}\right)_{0.98} \cdot 0.7 \mathrm{H}_{2} \mathrm{O}$, which has a high surface area $\left(238 \mathrm{~m}^{2} \mathrm{~g}^{-1}\right)$ and also a high external surface $\left(144 \mathrm{~m}^{2} \mathrm{~g}^{-1}\right)$, together with high micro- and mesopore volume. A $99 \%$ conversion and a 70:30 Diels-Alder/Mannich adducts ratio, after $24 \mathrm{~h}$ at $50^{\circ} \mathrm{C}$, was achieved. 
In 2013 Srinivas et al. proposed, for the first time, the use of zirconium phenyl phosphonate phosphite (ZrPP), with similar amounts of phenylphosphonate and phosphite groups, as a solid acid catalyst for producing polyol esters by esterification of glycerol or trimethylolpropane with a fatty acid [37]. The catalyst was prepared by adding a solution of zirconium oxychloride in water to a solution of phenyl phosphonic and phosphorous acids.

The catalytic tests were carried out by using trihydroxy alcohols (glycerol and trimethylolpropane, TMP) as representative polyols and oleic acid (OA) was considered as a representative fatty acid. The catalyst showed high catalytic activity and most importantly the diester + triester (DE + TE) selectivity. Specifically, it increased with increasing OA/polyol molar ratio. As an example, when the OA: polyol molar ratio was $4: 1$, the reaction temperature was $180^{\circ} \mathrm{C}$ and the reaction time was $1 \mathrm{~h}$, the selectivity for DE + TE was $92.3 \mathrm{~mol} \%$ in the case of glycerol and $86.0 \mathrm{~mol} \%$ in the case of TMP. Polyol conversion was $100 \%$ at these conditions: this is the highest selectivity achieved so far over a solid catalyst. As observed by other authors, the hydrophobic character of the catalyst played a key role to drive the equilibrium toward DE + TE esters.

Calogero et al. prepared zirconium phosphate phosphonates bearing both a hydrophobic and a L-proline group covalently bonded to the layer surface [38]. The general formula of the solid catalysts was $\mathrm{Zr}\left(\mathrm{PO}_{3}-\mathrm{OProl}\right)_{x}\left(\mathrm{PO}_{3} \mathrm{R}\right)_{2-\mathrm{x}}$, where Prol = proline group $\left(\mathrm{C}_{5} \mathrm{H}_{8} \mathrm{O}_{2} \mathrm{~N}\right)$ and $\mathrm{R}=$ methyl and / or phenyl group. A typical L-proline-mediated organic reaction is the aldol addition which is one of the most important reaction in organic synthesis for the $\mathrm{C}-\mathrm{C}$ bond formation. The catalytic activity of the L-proline functionalized zirconium phosphate methyl and/or phenylphosphonates was tested in the asymmetric aldol addition of $p$-nitrobenzaldehyde to cyclohexanone. It was found that the catalyst bearing both P-Me and P-Ph groups together with the L-proline group was the best catalyst. It was speculated that the P-Me group is crucial to separate the bulky group P-Ph and P-Prol, while the P-Ph group is necessary to increase the hydrophobicity of the solid surface. Good results were obtained in both $\mathrm{DMF} / \mathrm{H}_{2} \mathrm{O}$ 9:1 (conv. 70\%, ee 96\%) and water (conv. 71\%, ee 91\%). Unfortunately, the recovering and recycling tests were unsatisfactory, due to the hydrolysis of phosphate ester bond that links the L-proline group to the inorganic layer.

\section{Zirconium Phosphates/Phosphonates as Solid Supports for Catalytically Active Species}

An important key issue in catalysis is the development of catalysts with high thermal and chemical stability, and ease of recovery. The optimization of these properties can be addressed by immobilizing the catalyst on a specific and suitable solid support. Zirconium phosphates and phosphonates have been employed as supports for several catalytic active species among which are organometallic complexes and metal ions, noble metal nanoparticles, and metal oxide nanoparticles.

The literature data reported below has been summarized in Table 2.

Panda et al. immobilized $\mathrm{Cr}$ (III) ions on mesoporous $\mathrm{ZrP}(\mathrm{Cr}-\mathrm{mZrP})$ and evaluated the catalytic activity towards the oxidation of allylic and benzylic compounds to their corresponding carbonyl compounds [39]. Mesoporous $\mathrm{ZrP}$ was prepared as previously described by the same authors [23]. Then, a solution of $\mathrm{Cr}\left(\mathrm{NO}_{3}\right)_{3}$ was added to the calcined $\mathrm{m}-\mathrm{ZrP}$ product. The $\mathrm{Cr} / \mathrm{Zr}$ molar ratio in $\mathrm{Cr}-\mathrm{m}-\mathrm{ZrP}$ was 0.138 . Diffuse reflectance analysis suggested the presence of trivalent chromium in an octahedral coordination. Moreover, it was found that the incorporation of chromium into $\mathrm{m}-\mathrm{ZrP}$ increases the number of the Lewis acid sites (weak acidic sites), while decreasing the number of Bronsted acid sites with respect to pristine $\mathrm{m}-\mathrm{ZrP}$. However, the total acidity increases $\left(2.29 \mathrm{mmol}_{\mathrm{NH} 3} \mathrm{~g}^{-1}\right)$ with respect to that of pristine $\mathrm{m}-\mathrm{ZrP}\left(1.8 \mathrm{mmol}_{\mathrm{NH} 3} \mathrm{~g}^{-1}\right)$. The conversion of ethyl benzene to acetophenone reached $91 \%$ with $100 \%$ selectivity using a $10 \mathrm{wt} \%$ loading of the catalyst, $20 \mathrm{mmol}$ of $\mathrm{H}_{2} \mathrm{O}_{2}$, at $80^{\circ} \mathrm{C}$ for $12 \mathrm{~h}$. The catalytic test performed after the third cycle showed a slight decrease in the conversion, probably caused by leaching of chromium. $\mathrm{Cr}-\mathrm{m}-\mathrm{ZrP}$ was also used for the oxidation of several industrially important benzylic and allylic compounds and in all cases high conversions with $100 \%$ selectivity for the desired benzylic or allylic carbonyls was achieved. 
Liu et al. reported the use of chromium incorporated $\mathrm{m}-\mathrm{ZrP}$ as a catalyst for the conversion of carbohydrates (fructose) into HMF [40]. The best result was obtained at the reaction temperature of $120^{\circ} \mathrm{C}$, in ionic liquid 1-butyl-3-methylimidazolium chloride, where the fructose conversion reached $100 \%$, and the yield of HMF achieved a maximum value of $94.5 \%$ after $2 \mathrm{~h}$.

Table 2. Summarizing table on the use of zirconium phosphates and its organic derivatives as solid supports for catalytically active species.

\begin{tabular}{|c|c|c|}
\hline Catalysts & Catalytic Reaction & Reference \\
\hline \multirow{2}{*}{$\mathrm{Cr}(\mathrm{III})$ immobilized on $\mathrm{m}-\mathrm{ZrP}$} & Oxidation of allylic and benzylic compounds & [39] \\
\hline & Conversion of fructose into HMF & [40] \\
\hline $\begin{array}{l}\mathrm{Fe}(\mathrm{III}) \text { immobilized on window-type } \\
\text { organic zirconium phosphonate }\end{array}$ & Formaldehyde decomposition & [41] \\
\hline $\begin{array}{l}\mathrm{Fe}(\mathrm{Salen}) \text { and } \mathrm{Cu}(\text { Salen}) \text { complexes } \\
\text { supported on microcystalline } \mathrm{ZrP}\end{array}$ & Cyclohexene oxidation & {$[42,43]$} \\
\hline $\begin{array}{l}\mathrm{Rh}(\mathrm{III}) \text { and } \mathrm{Ir}(\mathrm{III}) \text { complexes } \\
\text { intercalated into } \mathrm{ZrP}\end{array}$ & Visible light driven $\mathrm{H}_{2}$ production & [44] \\
\hline $\begin{array}{l}\mathrm{ClRh}\left(\mathrm{PPh}_{3}\right)_{3} \text { immobilized on } \\
\text { ethoxysilane-modified } \mathrm{ZrP}\end{array}$ & Olefin hydrogenation & [45] \\
\hline $\mathrm{Co}-\mathrm{Ru}$ immobilized on $\mathrm{ZrP} / \mathrm{SiO}_{2}$ & Fischer-Tropsch reaction & [46] \\
\hline \multirow{2}{*}{ Pd NPs supported on $\mathrm{ZrP}$} & Synthesis of 1,6-hexanediol from HMF & [47] \\
\hline & Heck reaction & [48] \\
\hline $\begin{array}{l}\text { Pd NPs supported on } \\
\text { zirconium phosphonates }\end{array}$ & Suzuki-Miyaura coupling reaction & [49] \\
\hline $\begin{array}{l}\text { Pd fluorinated complexes intercalated into } \\
\text { microcrystalline } \mathrm{ZrP}\end{array}$ & Sonogashira and Heck reactions & [50] \\
\hline $\mathrm{TiO}_{2}$ pillared $\mathrm{ZrP}$ & Degradation of methyl orange & [51] \\
\hline $\mathrm{TiO}_{2-x}$ clusters grafted on $\mathrm{ZrP}$ nanosheets & Degradation of methylene blue & [52] \\
\hline $\mathrm{Ag} @ \mathrm{AgCl} /$ nanosized ZrP & Degradation of Rhodamine B & [53] \\
\hline $\begin{array}{l}\text { Vanadium phosphorus oxide } \\
\text { supported on } \mathrm{ZrP}\end{array}$ & dehydration of glycerol & {$[54]$} \\
\hline $\begin{array}{l}\text { 1-butyl-3-methylimidazolium chloride } \\
\text { intercalated into layered } \theta-Z r P\end{array}$ & $\begin{array}{c}\text { synthesis of propylene carbonate from } \mathrm{CO}_{2} \\
\text { and propylene oxide }\end{array}$ & [55] \\
\hline
\end{tabular}

Mo et al. immobilized $\mathrm{Fe}(\mathrm{III})$ ions on a new window-type porous organic zirconium phosphonate hybrid material having the formula $\left.\mathrm{Zr}_{5}\left(\mathrm{HPO}_{4}\right)_{6} \mathrm{O}_{3} \mathrm{PCH}_{2} \mathrm{~N}\left(\mathrm{CH}_{2} \mathrm{CH}_{2} \mathrm{COOH}\right) \mathrm{CH}_{2} \mathrm{PO}_{3}\right](\mathrm{ZrNCP})$, based on b-alanine- $N, N$-dimethylidenephosphonate groups bonded to adjacent inorganic layers, thus creating windows and, therefore, porosity [41]. Moreover, the presence of both nitrogen atoms and carbonyl groups in the organic chains allowed the coordination of metal ions with the wall of pores by ion exchange. The [ZrNCP-Fe(III)] catalyst was tested in the decomposition of formaldehyde, a dangerous enemy to human health, into non-toxic species. It was found that the above catalyst has a relative high activity in the decomposition of a $40 \%$ formaldehyde solution and $90.1 \%$ of formaldehyde conversion can be obtained at $80^{\circ} \mathrm{C}$ in $4 \mathrm{~h}$. A comparative experiment revealed that only $51 \%$ of formaldehyde can be oxidized in the absence of the catalyst. Recyclability tests showed that the conversion of formaldehyde (40\%) was still more than $80 \%$ and about $76 \%$ after the third and fourth cycle, respectively.

Organometallic complexes were also immobilized over zirconium phosphates. Colon et al. published in 2012 a paper dealing with the intercalation of a pyrazolate-bridged platinum(II) bipyridyl dimer onto $\theta-Z r P$, having an interlayer distance of $10.3 \AA$ [56]. The complex-exchanged ZrP samples were prepared by contacting suspensions of $\mathrm{ZrP}$ in 1:1 ethanol:water solutions of the tetrafluoroborate complex salt. Materials with different catalyst loadings were prepared by changing the Pt:ZrP molar ratio used in the suspension over a wide range (1:30-1:1). The ZrP underwent a color change from pale 
yellow to blue-gray during the intercalation process. Upon intercalation of the complex, the interlayer distance increases up to $15.6 \AA$ A The binding energies obtained by XPS analysis are consistent with an oxidation state intermediate between $\mathrm{Pt}(\mathrm{II})$ and $\mathrm{Pt}(\mathrm{III})$.

An intercalation reaction carried out in the presence of a reducing agent provided a yellow-brown material and the oxidation state of the Pt metal center is closer to +1 .

However, information about the catalytic properties of the complex-exchanged $\mathrm{ZrP}$ materials were not reported by the authors.

Salen complexes, containing the ligand coming from $\mathrm{N}, \mathrm{N}$-bis(salicylidene)-ethylenediamine $\left(\mathrm{H}_{2} \mathrm{Salen}\right)$, are used for the oxidation of alkenes in the presence of peroxides as oxidants. Khare et al. immobilized Salen complexes, including $\mathrm{Fe}(\mathrm{Salen})$ and $\mathrm{Cu}$ (Salen), on microcrystalline $\alpha$-ZrP and tested the catalytic activity in the cyclohexene oxidation with dry tertbutylhydroperoxide (TBHP) as an oxidant $[42,43]$. The heterogeneous catalysts were prepared by a two-step procedure. First, Fe(III) or $\mathrm{Cu}$ (II) ions were exchanged in microcrystalline $\alpha-\mathrm{ZrP}$ to form the $\alpha-\mathrm{ZrP} \cdot \mathrm{Fe}(\mathrm{III})$ or $\alpha-\mathrm{ZrP} \cdot \mathrm{Cu}$ (II) precursors. Then, intercalation of Salen into $\alpha-\mathrm{ZrP} \cdot \mathrm{Fe}(\mathrm{III})$ or $\alpha-\mathrm{ZrP} \cdot \mathrm{Cu}(\mathrm{II})$ to form $\alpha-\mathrm{ZrP} \cdot \mathrm{Fe}$ (Salen) or $\alpha-\mathrm{ZrP} \cdot \mathrm{Cu}$ (Salen) was carried out by the flexible ligand technique. Specifically, Salen was added to the above precursors and stirred at $423 \mathrm{~K}$ in an oil bath for $4 \mathrm{~h}$ under nitrogen gas flow. The resulting material was extracted with methanol to remove the excess of ligand, then washed with $\mathrm{NaCl}$ solution to remove uncomplexed metal ions and finally washed with double distilled water. After reaction with Salen, the precursors' colors changed from yellow to brown (with $\mathrm{Fe}(\mathrm{III})$ ), and from blue to green (with $\mathrm{Cu}(\mathrm{II})$ ). The interlayer distance of the host $\mathrm{ZrP}$ increased from $7.40 \AA$ to $8.98 \AA$ and to $9.87 \AA$, for $\alpha-\mathrm{ZrP} \cdot \mathrm{Fe}(\mathrm{Salen})$ and $\alpha-\mathrm{ZrP} \cdot \mathrm{Cu}(\mathrm{Salen})$, respectively. The catalytic activity of $\alpha-\mathrm{ZrP}$, Salen complexes, and supported Salen complexes was investigated separately in the oxidation of cyclohexene by using dry TBHP as an oxidant. It was observed that $\alpha$-ZrP was catalytically inactive. The catalysts' (Salen) complexes were active in homogeneous reactions, where cyclohexene was oxidized to cyclohexene oxide, cyclohexanol, and cyclohexenone in both cases. The $\alpha$-ZrP.(Salen) complexes were active for the oxidation of cyclohexene to cyclohexene oxide, cyclohexanol, and cyclohexanone, which was the major product. The maximum conversion of cyclohexene was $18.04 \%$ and $26.71 \%$ with $\alpha-\mathrm{ZrP} \cdot \mathrm{Fe}(\mathrm{Salen})$ and $\alpha-\mathrm{ZrP} \cdot \mathrm{Cu}(\mathrm{Salen})$, respectively. These values are lower than those obtained in the corresponding homogeneous reactions, being $25.99 \%$ and $30.56 \%$ with $\mathrm{Fe}(\mathrm{Salen})$ and $\mathrm{Cu}(\mathrm{Salen})$, respectively. However, the authors highlighted the fact that the recovery of the catalyst was not possible in the case of homogeneous catalysts, and that the yields of the products were based on the internal standard (dodecane) and the consumption of TBHP was determined iodometrically after each catalytic reaction. Moreover, they found that the heterogeneous catalysts were stable enough for oxidation of cyclohexene for six cycles without significant deterioration.

$\mathrm{ZrP}$ was also used as the host material for photo-active metal complexed catalysts. Mori and Yamashita reported the intercalation of $\mathrm{Rh}(\mathrm{III})$ and $\mathrm{Ir}(\mathrm{III})$ complexes into $\mathrm{ZrP}$ for $\mathrm{H}_{2}$ production driven by visible light [44]. The molecular-based photosystems in homogeneous solutions studied for photo-induced $\mathrm{H}_{2}$ production generally consist of several components, including a photosensitizer for the absorption of visible-light, an electron relay (generally methyl viologen) to quench the excited photosensitizer via an electron transfer, a water reduction catalyst to produce $\mathrm{H}_{2}$, and sacrificial reagents to serve as an electron source. In their work, Mori and Yamashita used a cyclometalated Ir(III) complex acting as photosensitizer, and a tris-2,2'-bipyridyl rhodium(III) complex acting as proton reduction catalyst. Both species were intercalated in $\mathrm{ZrP}$ by using an enlarged form, having an interlayer distance of $10.3 \AA$. X-ray absorption fine structure (XAFS) measurements indicated that both Ir and Rh complexes did not undergo structural change around metal environments upon intercalation. However, photoluminescence emission due to the Ir complex of the Ir-Rh/ZrP was blue shifted with respect to the free complex in acetonitrile at room temperature because of the rigidochromism effect and the excited state of Ir complex undergoing oxidative quenching by the neighboring Rh complex. The photocatalytic $\mathrm{H}_{2}$ production was studied by suspending the powdered $\mathrm{Ir}-\mathrm{Rh} / \mathrm{ZrP}$ in a $90 \%$ $\mathrm{H}_{2} \mathrm{O}$-acetonitrile solution in the presence of triethylamine as a sacrificial reagent. Then, the sample 
was irradiated by using a Xe lamp $(\lambda>420 \mathrm{~nm})$. The catalytic activity of $\mathrm{Ir}-\mathrm{Rh} / \mathrm{ZrP}$ was higher than that obtained in homogeneous conditions by a factor of 5 . The co-intercalation of both complexes in $\mathrm{ZrP}$ facilitated the direct electron transfer from the photosensitizer Ir complex to the proton reduction catalyst Rh complex without an electron mediator.

A Rh-based Wilkinson's catalyst, $\mathrm{ClRh}\left(\mathrm{PPh}_{3}\right)_{3}$, was immobilized on $\mathrm{ZrP}$ which was modified by reaction with an ethoxysilyl group containing a phosphine linker, $(\mathrm{EtO})_{3} \mathrm{Si}\left(\mathrm{CH}_{2}\right)_{3} \mathrm{PPh}_{2}$ [45]. The linker was covalently bonded to the $\mathrm{ZrP}$ surface through $\mathrm{P}-\mathrm{O}-\mathrm{Si}$ bonds involving the $-\mathrm{POH}$ groups of the $\mathrm{ZrP}$ layers and the ethoxysilyl groups of the linker. Solid-state NMR analysis proved the occurrence of up to three $\mathrm{P}-\mathrm{O}-\mathrm{Si}$ bonds, since no unreacted ethoxy groups were detected. Microprobe analysis suggested that the silane linker resided mostly on the surface of the support material, and practically does not intercalate. The immobilized Rh complex has been obtained by a ligand exchange reaction of the $\mathrm{ZrP}$-phosphine linker system with a Wilkinson's catalyst $\mathrm{ClRh}\left(\mathrm{PPh}_{3}\right)_{3}$ at room temperature. The presence and retention of the catalyst on the surface is indicated by the orange color of the support. Then, the supported catalyst was tested in olefin hydrogenation using dodecene as the substrate. As a first test, it has been established that the unmodified $\mathrm{ZrP}$ support does not catalyze the catalytic reaction. As expected, no $\mathrm{H}_{2}$ uptake takes place under the standard conditions with $\mathrm{ZrP}$, while the Wilkinson's catalyst in solution exhibited the usual and characteristic activity. The catalytic test carried out with the supported Wilkinson's catalyst showed that there is no induction period and that during the first run the catalyst quantitatively hydrogenates the substrate within $23 \mathrm{~h}$. It is surprising that when the catalyst is recycled in a batch-wise manner, the activity increases and the hydrogenation is finished within $13 \mathrm{~h}$, during the 15th cycle: this is the most active and recyclable immobilized hydrogenation catalyst so far.

Zirconium phosphates and phosphonates also turned out to be suitable supports for noble metal nanoparticles with catalytic activity.

A cobalt-based catalyst was immobilized on a $\mathrm{ZrP} / \mathrm{SiO}_{2}$ support and used in Fischer-Tropsch synthesis. Co-based catalysts supported on oxides generally exhibit high catalytic activity and selectivity to linear paraffinic hydrocarbons with a low activity for the water-gas shift reaction [46,57-60]. They are used in combination with promoters such as $\mathrm{Ru}, \mathrm{Zr}$, $\mathrm{Ti}$, and $\mathrm{La}$ which have different roles, including tuning the metal-support interaction and reducibility [46]. The composite $\mathrm{Co} / \mathrm{ZrP} / \mathrm{SiO}_{2}$ catalyst was also impregnated with a Ru precursor, since ruthenium acts as a promoter, and finally calcined at $400{ }^{\circ} \mathrm{C}$ so that the final catalyst had the following composition: $0.5 \mathrm{wt} \%$ $\mathrm{Ru} / 16.6 \mathrm{wt} \% \mathrm{Co} / 7.5 \mathrm{wt} \% \mathrm{ZrP} / 75.4 \mathrm{wt} \% \mathrm{SiO}_{2}$, with a different wt $\% \mathrm{P}(\mathrm{x})$ on $\mathrm{ZrP} / \mathrm{SiO}_{2}$, ranging from 0 to 2 . For $x=0.5$ the composite catalyst exhibited the best performances, with CO conversions of $98.9 \%$ and $85.3 \%$ at $10 \mathrm{~h}$ and $10 \mathrm{~h}$ on stream, respectively, while the $\mathrm{C}_{5}+$ yield reached $87.9 \%$. The authors speculated that the modification of $\mathrm{SiO}_{2}$ with a suitable amounts of phosphate groups of $\mathrm{ZrP}$ improved the ability of the support to stabilize Co nanoparticles toward aggregation which is mainly responsible for the catalyst's deactivation.

Among noble metal nanoparticles, palladium NPs are particularly efficient in catalysis and they have been heavily studied in a wide range of applications including hydrogenations, oxidations, carbon-carbon bond formation, and electrochemical reactions in fuel cells [61]. In the following examples, the catalytic behavior of Pd NPs immobilized on zirconium phosphates and phosphonates are reported.

Ebitani et al. in 2014 used a composite heterogeneous catalyst based on $\mathrm{ZrP}$ supporting Pd nanoparticles for the synthesis of 1,6-Hexanediol (HDO) from HMF by using formic acid as a hydrogen source [47]. HDO is used in the production of polyesters for polyurethane elastomers, coatings, adhesives, and polymeric plasticizers. The hydrogenolysis of HMF to HDO may proceed through two key reactions: (1) deoxygenation of the furan ring ( $\mathrm{CO}$ bond cleavage) by Brønsted-acid catalytic sites, and (2) hydrogenation of $\mathrm{C}=\mathrm{O}$ and $\mathrm{C}=\mathrm{C}$ bonds by the metal catalytic sites. The authors proved that the co-presence of $\mathrm{ZrP}$ Pd NPs supported on $\mathrm{ZrP}$, and formic acid is fundamental for an efficient single-step synthesis of HDO from HMF. As an example, with a $7 \mathrm{wt} \%$ of Pd NPs with an average 
particle size of $11.9 \mathrm{~nm}$, a HMF conversion rate of $96.9 \%$ was achieved, while the HDO yield was $42.5 \%$ for a reaction time of $21 \mathrm{~h}$ at $140{ }^{\circ} \mathrm{C}$. Moreover, the catalyst has been recycled without any significant loss of activity even after 5 cycles. To the best of our knowledge, this is the first example of a high yield of HDO from HMF without using high-pressure $\mathrm{H}_{2}$ gas.

Pd NPs with an average particle size of $9 \mathrm{~nm}$, immobilized on potassium exchanged $\mathrm{ZrP}$ was also successfully used in the Heck reaction, which is a useful and powerful tool to couple alkenes with aryl halides [48]. The Heck reaction is generally carried out in conventional dipolar aprotic media such us $N, N^{\prime}$-dimethylformamide (DMF) and $N$-methylpyrrolidone (NMP), which are undesirable due to their toxicity. In this paper, the authors studied the Heck coupling in the reaction of iodobenzene with methylacrilate to obtain methyl cinnamate, by choosing the azeotropic mixture $\mathrm{CH}_{3} \mathrm{CN} / \mathrm{H}_{2} \mathrm{O} 84 \%$ as a safer and easily recoverable reaction medium. The Heck reaction is characterized by a "release and catch" mechanism and the presence of a base is fundamental since it regenerates the active Pd species in the last step of the catalytic cycle. The use of potassium-exchanged $\mathrm{ZrP}$ was justified by the fact that it was previously observed by Clearfield et al. that the presence of cations, such as $\mathrm{Na}^{+}$and $\mathrm{K}^{+}$, improved the catalytic properties for metallic silver particles [62]. The Pd loading of the $\mathrm{ZrP} / \mathrm{Pd} \mathrm{NPs}$ system was about $10.6 \mathrm{wt} \%$. However, common dipolar aprotic media and some organic bases strongly bind the soluble palladium species, facilitating its dissolution from the support and consequent leaching into the products. In this regard, Petrucci et al. proved that the use of a heterogeneous base, namely diethylaminomethyl-polystyrene (PS-TEA), reduced the Pd leaching without compromising the catalytic activity. Indeed, at $120^{\circ} \mathrm{C}$ the conversion of iodobenzene to methyl cinnamate was $>99 \%$ in $3 \mathrm{~h}$, when the reaction was performed in the presence of PS-TEA, while the Pd leaching was lower than that observed with homogeneous TEA, being around $6 \mathrm{ppm}$, very close to the allowed upper limit of 5 ppm [63].

Nocchetti, Vaccaro et al. synthesized a novel layered zirconium phosphate-carboxyphosphonate (ZPGly), built from $N, N$-bis(phosphonomethyl)glycine, which was exfoliated by propylamine in water, thus producing stable colloidal dispersions of single sheets [49]. These colloidal dispersions were used to take up Pd(II) from a solution of palladium acetate. In this system, propylamine plays a dual role: as a swelling agent, making available the whole bulk of ZPGly to Pd ions, and as a co-ligand for Pd. The Pd loading was around $19 \mathrm{wt} \%$ and the Pd NPs' average size was $1.8 \pm 0.5 \mathrm{~nm}$. The catalytic behavior of this catalyst was studied in the Suzuki-Miyaura coupling between phenylboronic acid and aryl bromides by using a flow system at $70{ }^{\circ} \mathrm{C}$ and in the presence of $\mathrm{K}_{2} \mathrm{CO}_{3}$ as a base. The product was obtained with high yields (96-98\%), even after three cycles, and with negligible Pd leaching (5 ppm after the first cycle and 3 ppm after the third cycle).

Perry et al. used porous zirconium phosphonates bearing covalently bonded bipyridine moieties, with surface area in the range $350-530 \mathrm{~m}^{2} \mathrm{~g}^{-1}$, as support for Pd NPs [64]. The supports were first treated with palladium acetate in acetone and then $\mathrm{Pd}(\mathrm{II})$ was reduced in a $\mathrm{H}_{2}$ atmosphere at elevated temperatures $\left(250-450{ }^{\circ} \mathrm{C}\right)$ to form 2 to $4 \mathrm{~nm}$ particles, or by reflux in ethanol to form 10 to $12 \mathrm{~nm}$ diameter particles. The nanoparticles are dispersed within the phosphonate matrix and do not aggregate upon heating, even in the absence of surfactants and stabilizing agents. However, the catalytic behavior was not investigated.

Sun et al. reported in 2014 a work showing, for the first time, the direct intercalation of fluorous palladium complexes into microcrystalline $\alpha-\mathrm{ZrP}$ [50]. The authors speculated that the formation of hydrogen bonds between the hydroxyl groups of $\mathrm{ZrP}$ and the fluorous segments of the metal complexes promoted the intercalation reaction. The obtained heterogeneous catalysts were tested in the Sonogashira and Heck reactions. The authors reported that the heterogeneous $\mathrm{Pd}$ complex/ZrP catalysts were successfully used in the Sonogashira reaction of phenylacetylene with 4-nitro-iodobenzene. Specifically, a 100\% yield was achieved with the Pd-chlorofluorinated complexes immobilized on $\alpha-\mathrm{ZrP}$, and the catalyst could be recovered and reused up to 5 times without loss of catalytic activity at ca. $140{ }^{\circ} \mathrm{C}$. The catalytic tests performed in the Heck reaction of methyl acrylate with nitro-iodobenzene provided a $100 \%$ yield during three consecutive cycles. These results 
suggested that intercalation into $\mathrm{ZrP}$ is a promising strategy to prepare heterogeneous catalysts based on polyfluorinated metal complexes for various reactions.

$\alpha-Z r P-b a s e d$ composites were also used for photocatalytic reactions. R. Chen et al. [51] reported the use of $\mathrm{ZrP} /$ butylamine intercalation compounds to intercalate $\mathrm{TiO}_{2}$ particles obtained by hydrolysis of a tetrabutyl titanate solution and hydrothermal treatment. Several titania-pillared $\alpha-\mathrm{ZrP}$ materials were prepared with a total $\mathrm{TiO}_{2}$ amount in the range of $0.8 \mathrm{wt} \%-4.5 \mathrm{wt} \%$, while the amount of surface $\mathrm{TiO}_{2}$ goes from 0 to $1.24 \mathrm{wt} \%$, according to EDX-SEM analysis. The specific surface area was found to increase with increasing the amount of $\mathrm{TiO}_{2}$. The photocatalytic tests were carried out in the degradation of methyl orange (MO) solutions under ultraviolet irradiation at room temperature and under stirring. When titania-loading increased from $0.8 \mathrm{wt} \%$ to $1.7 \mathrm{wt} \%$, the photocatalytic degradation efficiency increased from $49 \%$ to $89 \%$; a further increase of the titania loading up to $4.5 \mathrm{wt} \%$ led to a decrease of the degradation percentage to $75 \%$. The authors speculated that the better photocatalytic activity of the $\mathrm{ZrP}-1.7 \mathrm{wt} \% \mathrm{TiO}_{2}$ sample, with respect to the others composites and to pure $\mathrm{TiO}_{2}$ anatase, can be mainly due to the higher $\mathrm{MO}$ adsorption capacity and more rapid $\mathrm{MO}$ adsorption rate, reaching $86 \%$ adsorption within $70 \mathrm{~min}$.

Liu et al. reported that in 2015 the grafting of titanium species, in the form of $\mathrm{TiO}_{2-\mathrm{x}}$ clusters with an average particle size of $2-5 \mathrm{~nm}$, to $\alpha-\mathrm{ZrP}$ nanosheets via chemical bonding with the $\mathrm{P}$ element [52]. The immobilization of titanium species on $\alpha-Z r P$ nanosheets was carried out via a modified post-grafting method, by calcination at $400{ }^{\circ} \mathrm{C}$ for $2 \mathrm{~h}$. The ZrP-Ti composites exhibited enhanced visible-light absorption properties compared with pure $\mathrm{TiO}_{2}$, so that they acted as better photicatalysts than pure $\mathrm{TiO}_{2}$ in the photodegradation of methylene blue (MB) under solar irradiation. A percentage of MB degradation of $100 \%$ was achieved over the $\mathrm{ZrP}-\mathrm{Ti}$ composite with the $\mathrm{P} / \mathrm{Ti}$ molar ratio of 1:1.

With respect to titania, silver/silver halide heterojunctions have the advantage of being active under visible light due to the plasmonic properties of silver nanoparticles. In this regard, silver-exchanged zirconium phosphate was used as precipitating agent for the synthesis of silver chloride particles having size $\leq 1 \mu \mathrm{m}$, thus obtaining $\mathrm{ZP} / \mathrm{AgCl}$ composites with different amounts of $\mathrm{AgCl}$ [53]. The photocatalytic activity of the $\mathrm{ZP} / \mathrm{AgCl}$ composites was tested in the degradation of Rhodamine $\mathrm{B}(\mathrm{RhB})$ under irradiation with a halogen lamp at room temperature and under stirring. It was proved that irradiation during the catalytic tests promoted the partial reduction of $\operatorname{Ag}(\mathrm{I})$ to $\operatorname{Ag}(0)$, with formation of the $\mathrm{Ag} @ \mathrm{AgCl}$ heterojunction. The sample with a $\mathrm{ZrP} / \mathrm{AgCl}$ weight ratio $=41 / 59$ exhibited the best catalytic properties, providing complete chromophore structure cleavage in $15 \mathrm{~m}$. When a pure $\mathrm{AgCl}$ sample was used as a catalyst, the concentration of the chromophore species after $30 \mathrm{~m}$ was about half of the initial one. Moreover, the catalytic activity of the best composite catalyst turned out to be high for three consecutive catalytic tests, with almost complete chromophore structure cleavage achieved in $10 \mathrm{~m}$ during the third run.

Vanadium phosphorus oxide (VPO) is another well-known catalytic material for the industrial selective oxidation of $\mathrm{n}$-butane to maleic anhydride [54]. This catalyst contains vanadium in several oxidation states: $5+(\alpha-, \beta-, \gamma-, \delta$-VOPO4 $), 4+\left((\mathrm{VO})_{2} \mathrm{P}_{2} \mathrm{O}_{7}\right)$ and $3+\left(\mathrm{VPO}_{4}\right)$. Chary et al. reported in 2014 a systematic study on the characterization of catalysts based on VPO supported on porous zirconium phosphate and their use in the catalytic dehydration of glycerol [54]. The heterogeneous catalysts, with VPO loadings ranging from 5-30 wt \%, were prepared by the solid-solid wetting method. Specifically, desired amounts of VPO precursor and porous zirconium phosphate powders were mixed together in a mortar and then the catalysts were calcined in the presence of nitrogen at $550{ }^{\circ} \mathrm{C}$. The surface area of the pure zirconium phosphate was $334 \mathrm{~m}^{2} \mathrm{~g}^{-1}$ and decreased with increasing the VPO content. SEM analysis showed that at lower loadings the VPO catalyst is well dispersed on the support, while at higher loadings the VPO particles are agglomerated, showing the characteristic rosette-shape clusters of $(\mathrm{VO})_{2} \mathrm{P}_{2} \mathrm{O}_{7}$ platelets. The catalysts contain both Lewis and Brønsted sites in different proportions, depending upon the VPO loadings on the support. The catalyst containing $20 \mathrm{wt} \%$ VPO exhibited the 
maximum number of accessible Brønsted and Lewis acidic sites and the best activity towards glycerol conversion $(100 \%)$ and acrolein selectivity $(65 \%)$ compared to other catalysts.

In recent years, Ionic liquids (ILs) have attracted interest for applications in many new fields, including catalysis [65-67]. In this regard, it was proven that ILs are effective in catalyzing coupling reactions to convert $\mathrm{CO}_{2}$ to valuable chemicals. A strategy to improve the catalyst efficiency is to immobilize ILs on an inorganic support. Sun et al. reported the intercalation of 1-butyl-3-methylimidazolium chloride (BMIMCl) into layered $\theta-\mathrm{ZrP}$ [55]. The immobilized BMIMCl was evaluated via a coupling reaction of $\mathrm{CO}_{2}$ and propylene oxide to synthesize propylene carbonate. It was found that $1.0 \mathrm{~g}$ of immobilized $\theta-\mathrm{ZrP} / \mathrm{BMIMCl}$ (containing $0.7 \mathrm{~g} \mathrm{BMIMCl}$ ) resulted in a yield of $78.9 \%$, which was slightly higher than that obtained with $0.7 \mathrm{~g}$ of neat $\mathrm{BMIMCl}(73.5 \%$, under the same conditions). The advantage of the immobilization of $\mathrm{BMIMCl}$ on $\theta-\mathrm{ZrP}$ is the possibility to easily recover the heterogeneous catalysts from the homogeneous liquid reaction mixture, while the recovery of un-supported $\mathrm{BMIMCl}$ is very difficult, since it dissolves in the product. Moreover, the recycled $\theta-\mathrm{ZrP} / \mathrm{BMIMCl}$ exhibited a performance close to that obtained in the first cycle.

\section{Conclusions and Future Perspectives}

This short review highlighted that zirconium phosphate and its derivatives still have great appeal in the field of heterogeneous catalysis, due to their versatility in terms of textural features and reactivity. The possibility to tune the surface area and its acidity, the porosity, and the nature of functional groups anchored on the particle surface, allows to design and synthesize tailor-made materials with optimized properties with respect to the desired catalytic process.

The present review also aims to introduce some new outlooks which are included in the "zirconium phosphate catalysts" Special Issue, thanks to the original contributions of researchers with well-recognized experience in the field of tetravalent metal phosphates and heterogeneous catalysis.

Acknowledgments: M.P. thanks the University of Perugia (Fondo Ricerca di Base 2014 D. D. n. 170, 23/12/2014, project title: Composti Organici ed Ibridi inorgano-organici del Selenio nella sintesi eco-compatibile di Molecole Bioattive) for financial support.

Author Contributions: M.P. collected literature data, wrote the paper and designed the graphical abstract.

Conflicts of Interest: The author declares no conflict of interest.

\section{References}

1. Clearfield, A.; Stynes, J.A. The preparation of crystalline zirconium phosphate and some observations on its ion exchange behavior. J. Inorg. Nucl. Chem. 1964, 26, 117-129. [CrossRef]

2. Clearfield, A.; Blessing, R.H.; Stynes, J.A. New crystalline phases of zirconium phosphate possessing ion-exchange properties. J. Inorg. Nucl. Chem. 1968, 30, 2249-2258. [CrossRef]

3. Clearfield, A.; Costantino, U. Comprehensive Supramolecular Chemistry; Alberti, G., Bein, T., Eds.; Pergamon, Elsevier Science Ltd. Press: New York, NY, USA, 1996; Volume 7, Chapter 4.

4. Alberti, G.; Torracca, E. Crystalline insoluble salts of polybasic metals-II. Synthesis of crystalline zirconium or titanium phosphate by direct precipitation. J. Inorg. Nucl. Chem. 1968, 30, 317-318. [CrossRef]

5. Capitani, D.; Casciola, M.; Donnadio, A.; Vivani, R. High yield precipitation of crystalline $\alpha$-zirconium phosphate from oxalic acid solutions. Inorg. Chem. 2010, 49, 9409-9415. [CrossRef] [PubMed]

6. Clearfield, A.; Duax, W.L.; Medina, A.S.; Smith, G.D.; Thomas, J.R. Mechanism of ion exchange in crystalline zirconium phosphates. I. Sodium ion exchange of alpha-zirconium phosphate. J. Phys. Chem. 1969, 73, 3424-3430. [CrossRef]

7. Rivera, E.J.; Figueroa, C.; Colon, J.L.; Grove, L.; Connick, W.B. Room-temperature emission from platinum(II) complexes intercalated into zirconium phosphate-layered materials. Inorg. Chem. 2007, 46, 8569-8576. [CrossRef] [PubMed]

8. Santiago, M.B.; Daniel, G.A.; David, A.; Casanas, B.; Hernandez, G.; Guadalupe, A.R.; Colon, J.L. Effect of Enzyme and Cofactor Immobilization on the Response of Ethanol Oxidation in Zirconium Phosphate Modified Biosensors. Electroanalysis 2010, 22, 1097-1105. 
9. Marti, A.A.; Colon, J.L. Photophysical characterization of the interactions among tris(2,2'-bipyridyl)ruthenium(II) complexes ion-exchanged within zirconium phosphate. Inorg. Chem. 2010, 49, 7298-7303. [CrossRef] [PubMed]

10. Pica, M.; Donnadio, A.; Capitani, D.; Vivani, R.; Troni, E.; Casciola, M. Advances in the chemistry of nanosized zirconium phosphates: A new mild and quick route to the synthesis of nanocrystals. Inorg. Chem. 2011, 50, 11623-11630. [CrossRef] [PubMed]

11. Pica, M.; Vivani, R.; Donnadio, A.; Troni, E.; Fop, S.; Casciola, M. Small is Beautiful: The Unusual Transformation of Nanocrystalline Layered $\alpha$-Zirconium Phosphate into a New 3D Structure. Inorg. Chem. 2015, 54, 9146-9153. [CrossRef] [PubMed]

12. Alberti, G.; Casciola, M.; Capitani, D.; Donnadio, A.; Narducci, R.; Pica, M.; Sganappa, M. Novel Nafion-zirconium phosphate nanocomposite membranes with enhanced stability of proton conductivity at medium temperature and high relative humidity. Electrochim. Acta 2007, 52, 8125-8132. [CrossRef]

13. Jimenez-Jimenez, J.; Maireles-Torres, P.; Olivera-Pastor, P.; Rodríguez-Castellón, E.; Jimenez-López, A.; Jones, D.J.; Roziere, J. Surfactant-assisted synthesis of a mesoporous form of zirconium phosphate with acidic properties. Adv. Mater. 1998, 10, 812-815. [CrossRef]

14. Alberti, G.; Casciola, M.; Costantino, U.; Vivani, R. Layered and pillared metal(IV) phosphates and phosphonates. Adv. Mater. 1996, 8, 291-303. [CrossRef]

15. Pica, M.; Donnadio, A.; Troni, E.; Capitani, D.; Casciola, M. Looking for New Hybrid Polymer Fillers: Synthesis of Nanosized $\alpha$-Type $\mathrm{Zr}(\mathrm{IV})$ Organophosphonates through an Unconventional Topotactic Anion Exchange Reaction. Inorg. Chem. 2013, 52, 7680-7687. [CrossRef] [PubMed]

16. Pica, M.; Donnadio, A.; D'Amato, R.; Capitani, D.; Taddei, M.; Casciola, M. Layered metal (IV) phosphonates with rigid pendant groups: New synthetic approaches to nanosized zirconium phosphate phenylphosphonates. Inorg. Chem. 2014, 53, 2222-2229. [CrossRef] [PubMed]

17. Casciola, M.; Capitani, D.; Donnadio, A.; Munari, G.; Pica, M. Organically modified zirconium phosphate by reaction with 1,2-epoxydodecane as host material for polymer intercalation: Synthesis and physicochemical characterization. Inorg. Chem. 2010, 49, 3329-3336. [CrossRef] [PubMed]

18. Donnadio, A.; Pica, M.; Capitani, D.; Bianchi, V.; Casciola, M. Layered zirconium alkylphosphates: Suitable materials for novel PFSA composite membranes with improved proton conductivity and mechanical stability. J. Memb. Sci. 2014, 462, 42-49. [CrossRef]

19. Donnadio, A.; Pica, M.; Subianto, S.; Jones, D.J.; Cojocaru, P.; Casciola, M.; Casciola, M. Promising Aquivion Composite Membranes based on Fluoroalkyl Zirconium Phosphate for Fuel Cell Applications. ChemSusChem 2014, 7, 2176-2184. [CrossRef] [PubMed]

20. Mosby, B.M.; Díaz, A.; Bakhmutov, V.; Clearfield, A. Surface Functionalization of Zirconium Phosphate Nanoplatelets for the Design of Polymer Fillers. ACS Appl. Mater. Interfaces 2014, 6, 585-592. [CrossRef] [PubMed]

21. Clearfield, A.; Thakur, D.S. Zirconium and titanium phosphates as catalysts: A review. Appl. Catal. 1986, 26, 1-26. [CrossRef]

22. Zhang, F.; Xie, Y.; Lu, W.; Wang, X.; Xu, S.; Lei, X. Preparation of microspherical $\alpha$-zirconium phosphate catalysts for conversion of fatty acid methyl esters to monoethanolamides. J. Colloid Interface Sci. 2010, 349, 571-577. [CrossRef] [PubMed]

23. Sinhamahapatra, A.; Sutradhar, N.; Roy, B.; Tarafdar, A.; Bajaj, H.C.; Panda, A.B. Mesoporous zirconium phosphate catalyzed reactions: Synthesis of industrially important chemicals in solvent-free conditions. Appl. Catal. A Gen. 2010, 385, 22-30. [CrossRef]

24. Sinhamahapatra, A.; Sutradhar, N.; Roy, B.; Pal, P.; Bajaj, H.C.; Panda, A.B. Microwave assisted synthesis of fine chemicals in solvent-free conditions over mesoporous zirconium phosphate. Appl. Catal. B Environ. 2011, 103, 378-387. [CrossRef]

25. Jain, A.; Shore, A.M.; Jonnalagadda, S.C.; Ramanujachary, K.V.; Mugweru, A. Conversion of fructose, glucose and sucrose to 5-hydroxymethyl-2-furfural over mesoporous zirconium phosphate catalyst. Appl. Catal. A Gen. 2015, 489, 72-76. [CrossRef]

26. Weingarten, R.; Kim, Y.T.; Tompsett, G.A.; Fernández, A.; Han, K.S.; Hagaman, E.W.; Conner, W.C., Jr.; Dumesic, J.A.; Huber, G.W. Conversion of glucose into levulinic acid with solid metal(IV) phosphate Catalysts. J. Catal. 2013, 304, 123-134. [CrossRef] 
27. Spielbauer, D.; Mekhemer, G.A.H.; Riemer, T.; Zaki, M.I.; Knözinger, H. Structure and Acidic Properties of Phosphate-Modified Zirconia. J. Phys. Chem. B 1997, 101, 4681-4688. [CrossRef]

28. Das, S.K.; Bhunia, M.K.; Sinha, A.K.; Bhaumik, A. Synthesis, Characterization, and Biofuel Application of Mesoporous Zirconium Oxophosphates. ACS Catal. 2011, 1, 493-501. [CrossRef]

29. Cheng, L.; Guo, X.; Song, C.; Yu, G.; Cui, Y.; Xue, N.; Peng, L.; Guo, X.; Ding, W. High performance mesoporous zirconium phosphate for dehydration of xylose to furfural in aqueous-phase. RSC Adv. 2013, 3, 23228-23235. [CrossRef]

30. Sinhamahapatra, A.; Sutradhar, N.; Pahari, S.; Bajaj, H.C.; Panda, A.B. Mesoporous zirconium phosphate: An efficient catalyst for the synthesis of coumarin derivatives through Pechmann condensation reaction. Appl. Catal. A Gen. 2011, 394, 93-100. [CrossRef]

31. Bellezza, F.; Cipiciani, A.; Costantino, U.; Fringuelli, F.; Orrù, M.; Piermatti, O.; Pizzo, F. Aza-Diels-Alder reaction of Danishefsky's diene with immines catalyzed by porous $\alpha$-zirconium hydrogen phosphate and SDS under solvent-free conditions. Catal. Today 2010, 152, 61-65. [CrossRef]

32. Alberti, G.; Casciola, M. Layered metal IV phosphonates, a large class of inorgano-organic proton conductors. Solid State Ionics 1997, 97, 177-186. [CrossRef]

33. Rosati, O.; Curini, M.; Montanari, F.; Nocchetti, M.; Genovese, S. $\alpha$-zirconium sulfophenylphosphonate as a catalyst for the synthesis of 3, 4-dihydropyrimidin-2 $(1 \mathrm{H})$-one derivatives under solvent free conditions. Catal. Lett. 2011, 141, 850-853. [CrossRef]

34. Zhou, Y.; Huang, R.; Ding, F.; Brittain, A.D.; Liu, J.; Zhang, M.; Xiao, M.; Meng, Y.; Sun, L. Sulfonic Acid-Functionalized $\alpha$-Zirconium Phosphate Single-Layer Nanosheets as a Strong Solid Acid for Heterogeneous Catalysis Applications. ACS Appl. Mater. Interfaces 2014, 6, 7417-7425. [CrossRef] [PubMed]

35. Lin, X.-Z.; Yuan, Z.-Y. Synthesis of Mesoporous Zirconium Organophosphonate Solid-Acid Catalysts. Eur. J. Inorg. Chem. 2012, 2661-2664. [CrossRef]

36. Lanari, D.; Montanari, F.; Marmottini, F.; Piermatti, O.; Orrù, M.; Vaccaro, L. New zirconium hydrogen phosphate alkyl and/or aryl phosphonates with high surface area as heterogeneous Brønsted acid catalysts for aza-Diels-Alder reaction in aqueous medium. J. Catal. 2011, 277, 80-87. [CrossRef]

37. Varhadi, P.; Kotwal, M.; Srinivas, D. Zirconium phenyl phosphonate phosphite as a highly active, reusable, solid acid catalyst for producing fatty acid polyol esters. Appl. Catal. A Gen. 2013, 462-463, 129-136. [CrossRef]

38. Calogero, S.; Lanari, D.; Orrù, M.; Piermatti, O.; Pizzo, F.; Vaccaro, L. Supported L-proline on zirconium phosphates methyl and/or phenyl phosphonates as heterogeneous organocatalysts for direct asymmetric aldol addition. J. Catal. 2011, 282, 112-119. [CrossRef]

39. Sinhamahapatra, A.; Sutradhar, N.; Pahari, S.K.; Pal, P.; Bajaj, H.C.; Jayachandran, M.; Panda, A.B. Allylic and Benzylic Oxidation over $\mathrm{Cr}^{\mathrm{III}}$-Incorporated Mesoporous Zirconium Phosphate with 100\% Selectivity. ChemCatChem 2011, 3, 1447-1450. [CrossRef]

40. Liu, B.; Ba, C.; Jin, M.; Zhang, Z. Effective conversion of carbohydrates into biofuel precursor5hydroxymethylfurfural (HMF) over Cr-incorporated mesoporous zirconium phosphate. Ind. Crops Prod. 2015, 76, 781-786. [CrossRef]

41. Mo, S.; Zhao, X.; Chen, Y.; Liu, L.; Wang, R.; Xu, Q. Synthesis and catalytic properties of a new window type hybrid porous zirconium Phosphonate Materials. Chem. Phys. 2013, 140, 228-235.

42. Khare, S.; Chokhare, R. Synthesis, characterization and catalytic activity of Fe(Salen) intercalated $\alpha$-zirconium phosphate for the oxidation of cyclohexene. J. Mol. Catal. A Chem. 2011, 344, 83-92. [CrossRef]

43. Khare, S.; Chokhare, R. Oxidation of cyclohexene catalyzed by $\mathrm{Cu}(\mathrm{Salen})$ intercalated $\alpha$-zirconium phosphate using dry tert-butylhydroperoxide. J. Mol. Catal. A Chem. 2012, 353-354, 138-147. [CrossRef]

44. Mori, K.; Aoyama, J.; Kawashima, M.; Yamashita, H. Visible-light driven $\mathrm{H}_{2}$ production utilizing iridium and rhodium complexes intercalated into a zirconium phosphate layered matrix. Dalton Trans. 2014, 43, 10541-10547. [CrossRef] [PubMed]

45. Silbernagel, R.; Díaz, A.; Steffensmeier, E.; Clearfield, A.; Blümel, J. Wilkinson-type hydrogenation catalysts immobilized on zirconiumphosphate nanoplatelets. J. Mol. Catal. A Chem. 2014, 394, 217-223. [CrossRef]

46. Bae, J.W.; Park, S.-J.; Woo, J.M.; Cheon, H.Y.; Ha, K.-S.; Jun, K.-W.; Lee, D.-H.; Jung, H.M. Enhanced Catalytic Performance by Zirconium Phosphate-Modified $\mathrm{SiO}_{2}$-Supported Ru-Co Catalyst for Fischer-Tropsch Synthesis. ChemCatChem 2011, 3, 1342-1347. [CrossRef] 
47. Tuteja, J.; Choudhary, H.; Nishimura, S.; Ebitani, K. Direct Synthesis of 1,6-Hexanediol from HMF over a Heterogeneous Pd/ZrP Catalyst using Formic Acid as Hydrogen Source. ChemSusChem 2014, 7, 96-100. [CrossRef] [PubMed]

48. Petrucci, C.; Cappelletti, M.; Piermatti, O.; Nocchetti, M.; Pica, M.; Pizzo, F.; Vaccaro, L. Immobilized palladium nanoparticles on potassium zirconium phosphate as an efficient recoverable heterogeneous catalyst for a clean Heck reaction in flow. J. Mol. Catal. A Chem. 2015, 401, 27-34. [CrossRef]

49. Costantino, F.; Vivani, R.; Bastianini, M.; Ortolani, L.; Piermatti, O.; Nocchetti, M.; Vaccaro, L. Accessing stable zirconium carboxy-aminophosphonate nanosheets as support for highly active Pd nanoparticles. ChemComm 2015, 51, 15990-15993. [CrossRef] [PubMed]

50. Lu, N.; Lin, K.-Y.; Kung, C.-C.; Jhuo, J.-W.; Zhou, Y.; Liuc, J.; Sun, L. Intercalated polyfluorinated Pd complexes in $\alpha$-zirconium phosphate for Sonogashira and Heck reactions. RSC Adv. 2014, 4, 27329-27336. [CrossRef]

51. Chen, R.; Wang, J.; Wang, H.; Yao, W.; Zhong, J. Photocatalytic degradation of methyl orange in aqueous solution over titania-pillared $\alpha$-zirconium phosphate. Solid State Sci. 2011, 13, 630-635. [CrossRef]

52. Zhou, Y.; Wang, A.; Wang, Z.; Chen, M.; Wang, W.; Sun, L.; Liu, X. Titanium functionalized $\alpha$-zirconium phosphate single layer nanosheets for photocatalyst applications. RSC Adv. 2015, 5, 93969-93978. [CrossRef]

53. Pica, M.; Nocchetti, M.; Ridolfi, B.; Donnadio, A.; Costantino, F.; Gentili, P.L.; Casciola, M. Nanosized zirconium phosphate $\mathrm{AgCl}$ composite materials: A new synergy for efficient photocatalytic degradation of organic dye pollutants. J. Mater. Chem. A 2015, 3, 5525-5534. [CrossRef]

54. Rajan, N.P.; Rao, G.S.; Pavankumar, V.; Chary, K.V.R. Vapour phase dehydration of glycerol over VPO catalyst supported on zirconium phosphate. Catal. Sci. Technol. 2014, 4, 81-92. [CrossRef]

55. Hu, H.; Martin, J.C.; Zhang, M.; Southworth, C.S.; Xiao, M.; Meng, Y.; Sun, L. Immobilization of ionic liquids in $\theta$-zirconium phosphate for catalyzing the coupling of $\mathrm{CO}_{2}$ and epoxides. RSC Adv. 2012, 2, 3810-3815. [CrossRef]

56. Rivera, E.J.; Barbosa, C.; Torres, R.; Rivera, H.; Fachini, E.R.; Green, T.W.; Connick, W.B.; Colon, J.L. Luminescence Rigidochromism and Redox Chemistry of Pyrazolate-Bridged Binuclear Platinum(II) Diimine Complex Intercalated into Zirconium Phosphate Layers. Inorg. Chem. 2012, 51, 2777-2784. [CrossRef] [PubMed]

57. Khodakov, A.Y.; Chu, W.; Fongarland, P. Advances in the development of novel cobalt Fischer-Tropsch catalysts for synthesis of long-chain hydrocarbons and clean fuels. Chem. Rev. 2007, 107, 1692-1744. [CrossRef] [PubMed]

58. Bao, J.; He, J.; Zhang, Y.; Yoneyama, Y.; Tsubaki, N. A core/shell catalyst produces a spatially confined effect and shape selectivity in a consecutive reaction. Angew. Chem. Int. Ed. 2008, 47, 353-356. [CrossRef] [PubMed]

59. Silva, D.O.; Scholten, J.D.; Gelesky, M.A.; Teixeira, S.R.; Dos Santos, A.C.B.; Souza-Aguiar, E.F.; Dupont, J. Catalytic gas-to-liquid processing using cobalt nanoparticles dispersed in imidazolium ionic liquids. ChemSusChem 2008, 1, 291-294. [CrossRef] [PubMed]

60. Zhang, Q.; Kang, J.; Wang, Y. Development of Novel Catalysts for Fischer-Tropsch Synthesis: Tuning the Product Selectivity. ChemCatChem 2010, 2, 1030-1058. [CrossRef]

61. Cookson, J. The Preparation of Palladium Nanoparticles. Platin. Metals Rev. 2012, 56, 83-98. [CrossRef]

62. Cheng, S.; Clearfield, A. Oxidation of ethylene catalyzed by silver supported on zirconium phosphate: Particle size and support effect. J. Catal. 1985, 94, 455-467. [CrossRef]

63. Committe for proprietary Medicinal Products (CPMP). Note for Guidance on Specification Limits for Residues of Metal Catalysts; The European Agency for the Evaluation of Medicinal Products: London, UK, 17 December 2002; Available online: http:/ / www.ema.europa.eu/docs/en_GB/document_library/Scientific_guideline/ 2009/09/WC500003588.pdf (17 December 2002).

64. Perry, H.P.; Law, J.; Zon, J.; Clearfield, A. Porous zirconium and tin phosphonates incorporating 2,2'-bipyridine as supports for palladium nanoparticles. Microporous Mesoporous Mater. 2012, 149, 172-180. [CrossRef]

65. Dupont, J.; de Souza, R.F.; Suarez, P.A.Z. Ionic liquid (molten salt) phase organometallic catalysis. Chem. Rev. 2002, 102, 3667-3691. [CrossRef] [PubMed] 
66. Zhao, D.B.; Wu, M.; Kou, Y.; Min, E. Ionic liquids: Applications in catalysis. Catal. Today 2002, 74, 157-189. [CrossRef]

67. Mehnert, C.P. Supported ionic liquid catalysis. Chem.-Eur. J. 2005, 11, 50-56. [CrossRef] [PubMed]

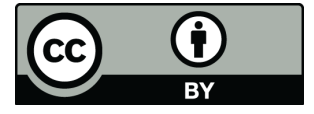

(c) 2017 by the author. Licensee MDPI, Basel, Switzerland. This article is an open access article distributed under the terms and conditions of the Creative Commons Attribution (CC BY) license (http:// creativecommons.org/licenses/by/4.0/). 